\title{
Complexo de perfuração: uma interpretação a partir da teoria da sedução generalizada*1
}

\section{Piercing complex: an interpretation based on the theory of generalized seduction}

Sarug Dagir Ribeiro*2 Fábio Roberto Rodrigues Belo*3

\begin{abstract}
Abordamos o complexo de perfuração via teoria da sedução generalizada, focando na chamada "sexualidade orificial" $e$ nas fantasias parentais, sobretudo a de arrombamentos dos orificios, que acabam inoculando na criança o medo de perfuração. Consideramos que o medo da perfuração remete à realidade da mensagem (vinda do adulto) e incita a criança a traduzir o corpo estranho interno que é propriamente intrometido nela, a saber, a excitação do sexual. E é nessa penetração originária (da mensagem do outro) que localizamos a mudança no vetor de explicação do medo paralisante presente no complexo de perfuração, que no pensamento bonaparteano sai da reação protocelular.
\end{abstract}

Palavras-chave: Mensagem, perfuração, sedução, tradução

*1 Este trabalho foi subvencionado pela Coordenação de Aperfeiçoamento de Pessoal de Nível Superior (Capes), está sob a orientação do Prof. Dr. Fábio R. R. Belo, e faz parte da tese de doutoramento em Psicologia intitulada "A sexualidade feminina em Marie Bonaparte: pontuações teóricas e clínicas à luz de Jean Laplanche", com expectativa de defesa em fevereiro/2020 junto ao PPG-Psicologia da Universidade Federal de Minas Gerais - UFMG (Belo Horizonte, MG, Brasil).

*2,3 Universidade Federal de Minas Gerais - UFMG (Belo Horizonte, MG, Brasil). 


\section{HISTÓRIA DA PSICANÁLISE}

\section{Introdução}

Nosso propósito é recuperar o conceito de "complexo de perfuração", de Bonaparte (1936/1952b), interpretando-o a partir da teoria da sedução generalizada (Laplanche, 1992). Veremos que esse conceito pode ser compreendido pela dimensão penetradora ou perfuradora da sedução originária (Laplanche, 1992; André, 1996; Ribeiro, 2016).

Dividimos este trabalho em quatro seções: na primeira, apresentaremos o conceito de "complexo de perfuração" e os argumentos bona-parteanos inspirados na biologia e na psicanálise, cujas referências excessivas à paleobiologia como que colocam "as amebas sobre o divã" (Amouroux, 2012, p. 186). Na segunda, discutiremos o papel do outro humano na inoculação do pulsional via teoria da sedução generalizada (Laplanche, 1992; 2015). Trabalharemos também a noção do "orificial" e das fantasias de arrombamento do orifício (Ribeiro, 2017; 2016). Na terceira seção, relacionaremos o complexo de perfuração com a violência da realidade da mensagem do outro (Laplanche, 1999b; Cardoso, 2017). E, na quarta e última seção, realizaremos uma digressão sobre o masoquismo no campo da teoria da sedução generalizada.

\section{O que é o complexo de perfuração?}

O conceito de "complexo de perfuração" na obra bonaparteana nasceu em meio aos estudos da autora em torno da sexualidade da mulher (Bonaparte, 1936/1952b; 1949/1967; Ribeiro \& Belo, 2017). Tal complexo seria o equivalente ao complexo de castração no menino. No entanto, para a autora (Bonaparte, 1936/1952b; 1948/1952c; 1950/1952d), um complexo não invalida o outro, mas ambos coexistem e coinfluenciam o desenvolvimento psicossexual da menina, em que, por exemplo, do lado da castração, situamos a inveja do pênis (Freud, 
1933[1932]/1976; 1924/1996b; 1924/1996c; 1923/1996d) e, do lado do complexo de perfuração, localizamos o medo da perfuração (que causa a morte). Nas palavras da autora:

O medo da efração da substância protoplásmica se manifesta então no terror de tantas virgens de serem penetradas, e se encontra, sem dúvida, na base de muita frigidez feminina. Sobre ela pode se elevar o edifício imponente, para o qual contribuem então todas as superestruturas do supereu, que nós encontramos sob a forma dos sintomas. (Bonaparte, 1936/1952b, p. 37; tradução nossa)

No trecho acima, os argumentos bonaparteanos apontam para um vetor que sai da célula para o psíquico. Assim, podemos definir tal complexo da seguinte maneira: "a mulher pode temer desse modo a penetração pelo homem [...] Então, a angústia da mulher diante da penetração sexual é uma angústia que se manifesta sobre o modo sadicamente terrificante pelo complexo de perfuração" (Bonaparte, 1936/1952b, p. 21 e 38; tradução nossa). Na elaboração desse conceito, a autora toma duas vias explicativas: a primeira é a via psicanalítica propriamente dita, que toma a cena originária (cena do coito dos pais) como uma cena de sedução que produz na menina a teoria sádica do coito (Freud, 1907/1974c; 1908/1974b; 1919/1980b), situação traduzida como uma cena de agressão sádica por parte do macho sobre a fêmea, impactando sobremaneira a evolução libidinal da menina, pois nela instaura-se uma angústia de efração (Bonaparte, 1935/1952a). A segunda via de explicação é a paleobiologia celular, sobre a qual a autora afirma que "a efração da substância dos viventes pode comportar sua destruição [...] essas reações celulares prototípicas se transferem em bloco ao psiquismo" (Bonaparte, 1949/1967, pp. 68-69; tradução nossa). Ou seja, para a autora, o psiquismo humano está ligado a certas reações biológicas presentes nas células, em um tipo de antropomorfismo celular. Reconhecemos que é no conceito de "complexo de perfuração" que se configura a faceta mais biologizante da psicanálise bonaparteana, daí um cenário fértil para a crítica ao desvio biologizante em psicanálise (Laplanche, 1999a; 2006). Não resta dúvida de que tal conceito é fruto da aliança que a autora realiza entre a psicanálise e a biologia (Amouroux, 2012), estando bem claro o sentido de direção do vetor de explicação: parte-se da célula para o psiquismo. Segundo Lebovici (1983), a formulação bonaparteana expressa de modo quase absoluto os dados da biologia em termos psicológicos.

O conceito de "complexo de perfuração" atravessa importantes textos de Bonaparte (1935/1952a; 1936/1952b; 1948/1952c; 1950/1952d), e, em todos eles, reproduz-se os dizeres que afirmam que a "pequena massa 


\section{HISTÓRIA DA PSICANÁLISE}

protoplasmática, em virtude dessa misteriosa adaptação da vida ao meio ao qual a envolve, deverá ter aprendido a reagir a qualquer sinal de ameaça exterior" (Bonaparte, 1936/1952b, p. 35; tradução nossa), o que implica que "todo organismo vivo, do micróbio ínfimo aos mamíferos, recuam diante dessa ameaça de efração ao interior de seu corpo" (p. 35; tradução nossa). Nessa linha de raciocínio, a autora defende a ideia de que a insatisfação frequente da mulher frente à relação sexual (frigidez) também "se funda sobre o medo vital da penetração ao interior do corpo" (Bonaparte, 1950/1952d, p. 36; tradução nossa). Em outro trecho, ela continua: "a penetração fecundadora do macho é sentida como uma efração intolerável" (Bonaparte, 1936/1952b, p. 38; tradução nossa).

Não obstante, esquematizando um pouco, ainda segundo a autora, a célula possui três modos de perfuração: o primeiro é a nutrição-defecação; o segundo, a reprodução (sexuada ou por cissiparidade); e o terceiro, a ferida causada por uma ameaça exterior. Os dois primeiros são benéficos, pois estão a serviço da vida: a fome provém da aspiração das células ao assimilar as substâncias do meio ambiente e a defecação, da eliminação daquilo não mais necessário; já do campo do amor (reprodução), provém da aspiração a união das células sexuais (óvulo e espermatozoide); o último, entretanto, a ameaça exterior, pode ocasionar, de fato, a morte (ferimento por arma branca ou de fogo, acidente, dentre outros).

Essas especulações paleo-psicanalíticas retiram do protótipo celular o conflito entre as pulsões sexuais (ou de conservação do eu) e a pulsão de morte. E esse conflito tem sua origem nesses três estados afetivos: o apetite, o amor e o medo (Bonaparte, 1936/1952b). Será por meio desse pensamento que a autora também explicará a fonte do masoquismo (Bonaparte, 1945/1973). Indo do masoquismo celular ao masoquismo feminino, a menina fantasia, ao ser penetrada pelo pênis, que seu corpo estará em situação de risco de dilaceramento e morte. A integridade narcísica de seu eu (Tarelho, 2016) estaria em oposição à possibilidade de efração do corpo gerada pela ameaça do pênis violador.

Notadamente, o complexo de perfuração é o medo, o desconforto ou a ansiedade de penetração, que causam sofrimento clinicamente significativo que pode assumir a forma de um medo paralisante impossibilitando a relação sexual.

Nessa pesquisa, o que nos interessa é a pulsão implantada na criança pela sedução do adulto. Assim, redirecionamos o vetor explicativo (centrífugo) presente no respectivo complexo de perfuração, ou seja, as "reações celulares prototípicas se transferem em bloco ao psiquismo" (Bonaparte, 1949/1967, pp. 68-69; tradução nossa), para procedermos outro direcionamento 
desse vetor (centrípeto), apontando para o pulsional que vem do outro na constituição tradutiva do medo de perfuração.

\section{Lanouzière, intérprete da sedução em Bonaparte}

A primeira articulação entre a teoria da sedução generalizada e a obra bonaparteana foi feita por Lanouzière (1991). A autora realiza um apanhado geral da sexualidade feminina nos estudos bonaparteanos e constata que, para Bonaparte, a sedução "aparece realmente como uma das causas possíveis de uma fixação a um modo primeiro de satisfação sexual" (Lanouzière, 1991, p. 126; tradução nossa). Isso significa, por exemplo, o despertar do clitóris da menina pelos cuidados do adulto na situação antropológica fundamental. No entanto, do ponto de vista bonaparteano, a sedução não é vista apenas como sedução restrita, mas como "uma sedução biológica... exercida pela "Mãe Natureza"' (p. 129; tradução nossa), concepção bem distinta da sedução generalizada desenvolvida por Laplanche (1992) anos mais tarde. Entretanto, o ponto curioso de suas formulações é que Lanouzière entende a sexualidade humana como uma evolução filogenética e paleobiológica, indo da célula para o psiquismo, e essa direção do vetor nomeamos de centrífugo. Tal posição é oposta ao que nomeamos por "vetor centrípeto", a partir do qual, na teoria da sedução generalizada, entende-se que a nossa constituição psíquica e nossa sexualidade são fundadas pelas mensagens comprometidas com o sexual que vêm do outro (Laplanche, 2015).

Nessa nossa escolha de fazer trabalhar a noção de "complexo de perfuração" pela teoria da sedução generalizada, existem mais dois fatores complicadores: o primeiro diz respeito à adoção, por Bonaparte (1951), da tradução do termo alemão Trieb por Instinct de maneira indiscriminada; outro fator diz respeito ao fato de a autora misturar as noções de "inconsciente" de Le Bon $(1875 ; 1911)^{1}$ e de Freud (1915/1980d). A respeito da confusão

${ }^{1}$ A teoria do inconsciente orgânico de Le Bon (1911), que irá influenciar enormemente os trabalhos bonaparteanos sobre o complexo de perfuração, implica que "o inconsciente orgânico [...] rege todos os fenômenos da vida: respiratórios, circulares etc. Estabilizado depois de um tempo pela acumulações hereditárias, ele funciona com uma admirável regularidade e à nossa revelia.” (p. 40, tradução nossa). 
dos termos alemães Trieb e Instinkt, Laplanche (2015) afirma que Marie Bonaparte, ao dizer num só sopro "pulsion ou instinct", acaba "misturando alhos com bugalhos" (p. 29). No intuito de fazer avançar a leitura de Lanouzière sobre a obra bonaparteana, articularemos essa teoria com outros elementos da teoria da sedução generalizada.

\section{Complexo de perfuração, passividade originária e sexualidade orificial}

Segundo André (1996), as origens femininas da sexualidade devem-se à natureza penetrável do corpo, ao gesto da efração originária vindo do outro e, então, tal gesto encontra-se pré-instalado no psicossoma da criança, uma vez que a pulsão (sexual e perversa) que vem do outro (cuidador/adulto) coloniza seu corpo.

O autor não foi o único a citar textos bonaparteanos nas suas argumentações, mas podemos afirmar que ele foi o primeiro que historicamente cita o conceito de "complexo de perfuração" na tentativa de desvinculá-lo do biologismo. Nesse sentido, Ribeiro (2017) adverte que "o poder enigmático da mensagem como efeito da passividade da criança perante o excesso de significação decorrente da sexualidade inconsciente do adulto, porém, não necessariamente dependente de elementos gestuais ou comportamentais como, por exemplo, a penetração" (pp. 116-117). Do nosso ponto de vista, esse último autor tem razão ao chamar nossa atenção para o fato de que a sexualidade inconsciente do adulto coloniza o corpo da criança não somente pelos gestos concretos típicos dos cuidados maternais, mas inclusive, e tão importante quanto, pela realidade da mensagem (composta de elementos verbais e não verbais) (Laplanche, 1999b) comprometida com o enigma do sexual.

É a passividade originária do infante e a inevitável inoculação traumática do sexual ${ }^{2}$ pelo adulto (Laplanche, 2015) que provavelmente faz André (1996) relacionar a sedução originária à penetração do corpo e do psiquismo. Esse entendimento é importante para os nossos propósitos porque assim podemos

2 "O Sexual é múltiplo, polimorfo. Descoberta fundamental de Freud, ele fundamenta-se no recalque, no inconsciente, na fantasia. É o objeto da Psicanálise. [...] é o resíduo inconsciente do recalque-simbolização do gênero pelo sexo" (Laplanche, 2015, p. 155). 
fazer trabalhar o conceito de "complexo de perfuração" na sedução originária, quer seja enquanto resultado do esforço tradutivo do bebê em decifrar as mensagens do outro, quer seja enquanto resultado de intromissões (Laplanche, 2008a) traduzidas por vias facilitadas da cultura como algo penetrante e ameaçador. Sendo assim, podemos aceitar que o medo diretamente relacionado à penetração dos limites corporais não é o resultado das reações celulares primitivas, como acreditava Bonaparte (1936/1952b), mas resultado de uma tradução específica do ataque sexual ao eu, ataque esse sempre presente na situação originária.

Em um dos seus estudos mais recentes, Ribeiro (2017) aponta que é

fundamental admitir que a existência de orifícios penetráveis no corpo, e a possibilidade de que sejam penetrados, estabelecem uma das formas por meio das quais a alteridade pode ser representada e, consequentemente, também definem uma das principais vias de representação do ataque pulsional. (pp. 117-118)

$\mathrm{O}$ autor ainda argumenta que a genitália externa feminina pode ser vista em sua positividade orificial e não em sua negatividade castrativa, "então, a diferença anatômica dos sexos pode encontrar seu lugar no inconsciente, que não comporta nenhum tipo de negação" (Ribeiro, 2016, p. 110). De acordo com o autor, portanto, haveria no inconsciente algum registro positivo do orifício, e, dessa forma, a primazia fálica é colocada em questão. Assim, como os orifícios corporais estão presentes em todos os seres humanos, é "possível propor, em lugar de 'feminilidade orificial', uma sexualidade orificial" (p. 110).

Desse modo, ao estabelecermos esse entendimento da sexualidade orificial, podemos fazer uma nova interpretação do texto bonaparteano ao analisarmos o medo da penetração como inerente não somente às mulheres, mas a todos os seres humanos, pois a situação antropológica fundamental está inteiramente acomodada na passividade radical do infante perante o caráter involuntário e invasivo do inconsciente (sexual) do adulto (Laplanche, 2015).

Dito isso, podemos não só pensar nos efeitos psíquicos e pulsionais da oposição interno-externo inerente à delimitação e fronteiras do eu com o recalcamento primário, mas, sobretudo, a tradução da penetração vem com o recalcamento secundário. Aliás, o código da penetração, por sua vez inclui-se na série dos cenários ditos originários, quer sejam esses a cena originária, a castração ou o Édipo, e que "se valem, como cenários criados pelo eu sob a pressão da pulsão e do desejo" (Laplanche, 1999b, p. 10; tradução nossa). Ou seja, a tradução da passividade originária se dá, com muita frequência, em termos de penetração, de intrusão, de rompimento de 


\section{HISTÓRIA DA PSICANÁLISE}

barreiras, de "arrombamentos de orifícios" (Ribeiro, 2016, p. 111), pois há uma via facilitadora da cultura que oferece códigos tradutivos que alimentam as fantasias sadomasoquistas cujo funcionamento convoca, muitas vezes, o penetrar/ser penetrado.

Assim, cabe destacar a "realidade da sedução" (Laplanche, 1999b, p. 10) como prioritária a esses outros cenários ditos originários. Dessa maneira, ninguém escapa da referência à penetração, a penetrabilidade do corpo, principalmente dos orifícios corporais, seja a boca, as narinas, os ouvidos, os olhos, a uretra, o ânus, a vagina, a pele (Anzieu, 1968; 1974) nos cuidados prestados pelo adulto na situação antropológica fundamental.

Segundo Ribeiro (2016) que "a feminilidade seja, desde épocas imemoriais, associada à posição penetrada, pode significar apenas a existência de um vício de tradução" (p. 111), que, por sua vez, em algum momento da história, passou a servir como instrumento de poder e de dominação dos homens sobre as mulheres, no chamado regime patriarcal. De acordo com Laplanche (1988), "a ferida é colocada, claro, como idêntica ao estatuto feminino e como resultado de um ato de agressão, mas também como a abertura, pelo menos virtual, do corpo: não unicamente como amputação, mas como buraco" (p. 269). Dessa maneira, é promissor pensar o complexo de perfuração via sexualidade orificial na medida em que, na situação antropológica fundamental, o bebê suscita, no adulto, fantasias pré-consciente/conscientes de arrombamento dos orifícios do corpo desse bebê, que são, pela censura moral e outros mecanismos repressores, contidas, e, por sua vez, implanta na criança o desejo, mais tarde metabolizado e traduzido como desejo de ser penetrado e de penetrar.

Podemos encontrar alguma alusão ao orificial nos textos bonaparteanos nos seguintes termos: "um tipo de engrama erótica convexa, pré-formadora da função erótica aparece na mulher, e se fixará dessa forma, em oposição ao engrama erótica côncava, que deverá ser aquela própria da mulher no coito" (Bonaparte, 1935/1952a, pp. 32-33; tradução nossa). O termo escolhido pela autora, "engrama", merece ser destacado: é uma marca duradoura. Por um lado, acreditamos, a partir da teoria laplancheana, que tal marca é proveniente do outro e não do próprio corpo, como a autora pressupõe. Essas marcas são provenientes das fantasias do outro que cuida do bebê.

Freud (1918[1917]/1980c), remetendo às pesquisas antropológicas sobre o ato da defloração em tribos australianas, refere-se a um ritual em que o hímen é perfurado, "o ato se realiza em duas partes, perfuração e relação sexual", ocasionando a "ruptura do hímen sem relação sexual e a 
relação sexual com finalidade de efetuar a ruptura" (p. 181). O autor alerta sobre a questão de que "a importância psicológica do ato da defloração é completamente deslocado em favor de suas consequências anatômicas" (Freud, 1918[1917]/1980c, p. 181). Costumeiramente, o ato da defloração geralmente sangra e o sangue em nossa cultura está associado à ideia de perigo. Assim, podemos pensar que também o sangramento da menstruação pode de alguma maneira ser traduzido ou associado a outros incômodos como a dor e o perigo, alimentando desse modo ideias e fantasias sádicas. Freud (1918[1917]/1980c) afirma: "a primeira ocasião da relação sexual é, certamente, um ato perigoso, sobretudo, se implicar fluxo de sangue" (p. 183), consequentemente produzindo na menina o medo dos primeiros acontecimentos relacionados à perfuração do hímen e subsequente defloração. Laplanche (1992) sinaliza que esse é um dos melhores textos freudianos quando o assunto é o papel do outro (o adulto) na constituição psíquica. Então,

a criança, mesmo possuindo certas montagens e aptidões adaptativas que começamos a conhecer bem, continua fundamentalmente destinada à Hilflosigkeit; ela precisa necessariamente ser substituída por alguém, tanto para a satisfação de suas necessidades quanto para a prevenção dos perigos. (Laplanche, 1992, p. 108)

Diríamos que a Hilflosigkeit (desamparo) do bebê não se limita à incapacidade de se ajudar na procura de meios para manter sua subsistência, como na procura de alimentos, mas também na incapacidade de evitar perigos. Portanto, a instauração do eu é pré-condição para esse discernimento. A propósito da angústia infantil, de acordo com o autor, o medo (Angst) é tanto uma reação a um perigo real como uma reação ao ataque pulsional interno inoculado na criança pelo inconsciente (sexual) do adulto, que, no texto freudiano (Freud, 1918[1917]/1980c), explica o desejo de castração pela mulher e pela mãe como sendo a base do tabu da virgindade. Freud oferece pistas de que o defloramento anatômico implica uma injúria narcísica, em um tipo de diminuição de valor. Em outros termos, o complexo de perfuração é capaz de precipitar um tipo de impotência psíquica que reabre as cenas da passividade originária. Percebemos a relação do complexo de perfuração com o narcisismo na medida em que há uma derivação ou projeção da efração do corpo para a efração egoica, ou, ainda, da defloração para a ameaça de dilaceramento do eu. Veremos com mais detalhes nas seções seguintes a concepção tradutiva desse complexo e, em seguida, sua relação com o masoquismo. 


\section{HISTÓRIA DA PSICANÁLISE}

\section{Fantasias de penetração e medo da perfuração: uma concepção tradutiva}

Nesta seção, atentamos sobre a concepção sádica do coito (Freud, 1905/1974d; 1907/1974c; 1926[1925]/1996a) já mencionada anteriormente, para frisar sua importância no campo das fantasias, como uma resposta tradutiva ao ataque pulsional inoculado pela alteridade na situação antropológica fundamental. Para Bonaparte (1935/1952a), a concepção sádica do coito está na base da característica predominante do complexo de perfuração, ou seja, o medo da agressão perfurante. Segundo a autora, a cena originária equivale a uma cena de sedução (Lanouzière, 1991), ocasião em que a criança começa a teorizar sobre o enigma da origem dos bebês, sobre a vinda de um irmãozinho ou mesmo sobre os assuntos próprios do mundo adulto. Nossos esforços se dão no sentido de fazer enxergar a sedução não como sedução restrita, como pensa Bonaparte (1935/1952a), mas enquanto sedução generalizada (Laplanche, 1992). Podemos, então, discutir que as formas do medo, no complexo de perfuração, vão depender da tradução que cada sujeito faz do enigma. Então, com base no que temos trabalhado até aqui, o medo terrificante da efração do corpo pode ser compreendido como uma tradução frente à situação de passividade originária.

Freud (1926[1925]/1996a), referindo-se a um caso clínico de Hans, afirma que "a ideia de ser devorado pelo pai dá expressão, em uma forma que sofreu degradação regressiva, a um terno impulso passivo de ser amado por ele num sentido genital" (p. 127). Isso significa que, no inconsciente, temos um conflito: existe, por um lado, o desejo edípico de ser penetrado pelo pai relacionado ao caráter sádico-anal e à identificação narcísica com a mãe, e, por outro, a defesa quanto à ameaça de efração. Desse modo, o medo em jogo no complexo de perfuração pode ser interpretado como sendo o medo de efração, mas também como um desejo de efração, dando origem a traduções possíveis para a fantasia de arrombamento mortífero, tal como postulam Ribeiro (2016) e André (1996).

$\mathrm{Na}$ metabolização tradutiva da cena originária as crianças usualmente buscam "a solução do mistério em alguma atividade comum ligada à função de micção ou defecação" (Freud, 1926[1925]/1996a, p. 202), atividades tidas como orificiais, além, é claro, daquelas "fantasias infantis de negar as relações sexuais dos pais e de transformar a mãe em uma virgem ilesa" (Freud, 1926[1925]/1996a, p. 192).

A sexualidade orificial (Ribeiro, 2016), não podemos nos esquecer, no percurso do desenvolvimento psicossexual implica as atividades 
masturbatórias aliadas às fantasias que lhe sucedem, e, por exemplo, na organização sádico-anal "é comum a introdução do dedo no ânus, na busca pela obtenção de prazer sexual. Ou seja, a pulsão se apoia (étayage/ Anlehnung) numa função de autoconservação que passa para o plano da sexualidade" (Laplanche, 1985, p. 25).

Na fase erótica anal, encontramos uma predominância sádica da pulsão, em que o orifício anal é estimulado, machucado pela atividade masturbatória de retenção e soltura, fenômeno de satisfação passível em outros orifícios corporais também. É na situação antropológica fundamental que as primeiras sensações nos orifícios foram sentidas, seja pelo dedo do adulto, seja pelos lábios do adulto, ou mesmo pelo mais singelo toque. Ribeiro (2016) chama a atenção para o fato de que

enquanto o psiquismo se constitui a partir da ação do outro sobre um corpo inicialmente fragmentado e indefeso, o sexual sempre será dominado por fantasias de penetração (tanto na forma ativa quanto passiva), por pulsões que compelem à penetração e por mecanismos que buscarão conter essas pulsões. (p. 110)

É nessa medida que os orifícios seduzem, que eles são, nas palavras de Freud (1910/1974a), antes de mais nada, encantadores. O adulto encontra-se em face do "encanto do orifício" (Freud, 1910/1974a, p. 115), despertando nele fantasias de arrombamento. Por outro lado, a criança também é seduzida pelos orifícios do outro, por exemplo, pelo orifício do mamilo por onde sai o leite morno, pelo sorriso que traz os lábios quentes e o beijo terno. Sobremaneira, esse mesmo sorriso, que nos acaricia, pode, ao mesmo tempo, ferir-nos, paralisando-nos de medo. Assim, cabe o alerta de Tarelho (2017), de que o outro é como o sol, pois pode nos queimar na violência das suas carícias.

Dessa maneira, o medo de perfuração é um desses possíveis mecanismos que buscam conter o pulsional transbordante interno que veio do outro na situação antropológica fundamental e inoculou-nos com seu enigma (Laplanche, 2015). Perfuração no sentido da penetração da mensagem percebida como ameaçadora, justamente pelo caráter involuntariamente invasivo do sexual desse adulto (Tarelho, 2017).

A primeira consequência de nossa pesquisa é reiterar que a sedução originária é perfurante e ameaçadora para todas as pessoas, na medida em que "a efração da sedução adulta no corpo da criança é universal, os orifícios são para ambos os sexos uma zona de trânsito libidinal" (Silva, 2012, p. 108). O complexo de perfuração é decisivo para ambos os sexos, pois ninguém escapa 


\section{HISTÓRIA DA PSICANÁLISE}

da sedução originária, dos efeitos traumáticos das mensagens endereçadas do outro. A segunda consequência é propor uma radical ruptura com o vetor centrífugo de explicação desse fenômeno psíquico, redirecionando o vetor para o sentido centrípeto, ou seja, as mensagens ameaçadoras vindas do outro e estando relacionadas às fantasias de arrombamento dos orifícios (Ribeiro, 2016). Contudo, como dito anteriormente, isso gera não apenas o medo, mas também "o desejo inconsciente de penetração" (Laplanche, 1999b, p. 18; tradução nossa), ou seja, de ser arrombado pelo outro.

Nesta seção, realizamos a inversão do vetor explicativo do complexo de perfuração, em que, em vez de sairmos da célula, partimos da mensagem do outro.

\section{Perfuração, masoquismo e teoria da sedução generalizada}

O complexo de perfuração concerne, de fato, ao tema do sadomasoquismo (Bonaparte, 1945/1973). Iremos aqui privilegiar os trabalhos de Laplanche (2008b; 2008c) em torno do masoquismo reflexivo e do modelo tradutivo do inconsciente (Laplanche, 2015; Tarelho, 2017), para analisarmos o medo da perfuração como uma tradução do ataque do pulsional (sexual) inoculado em nós pelo outro, e traduzido muitas vezes como fantasias de espancamento (Freud, 1919/1980b; 1924/1980a) e/ou fantasias quase delirantes de que o pênis irá, de fato, penetrar no corpo, causando a morte (Bonaparte, 1948/1952c).

Situamos, assim, o complexo de perfuração na justa medida de uma posição reflexiva entre duas metas: a de penetrar ou a de ser penetrado (Ribeiro, 2017). Quando levamos essa discussão para a problemática sadomasoquista, o penetrar implica o sadismo e o ser penetrado o masoquismo. Tendo em vista o par atividade/passividade, a agressão originária vem do outro para só depois se tornar autoagressão. Primeiro, o sujeito é agredido e pode ter prazer nessa posição, e só depois metaboliza essa agressão, e, então, ela torna-se autoagressão.

Desejar/temer ser agredido, ser perfurado ou ser passivo: tudo isso traduz a realidade sexual da mensagem da situação originária. Tais desejos/temores não são provenientes da biologia celular, como afirmam os postulados bonaparteanos. O que interessa é a dimensão tradutiva que envolve o complexo de perfuração enquanto defesa de uma mensagem (vinda do exterior) que ameaça a integridade do eu. Um domínio de 
realidade psíquica no limite ou na passagem entre os domínios da autoconservação e da sexualidade, em que o medo apoia-se na ferida biológica (sangue, corte, fissura, orifício) para produzir o medo/desejo psicológico da perfuração.

É preciso compreender que "o verdadeiro sentido da noção de apoio vem do fato sedutivo" (Tarelho, 2017, p. 27). Ou seja, "da agressividade em autoagressão que está ligada à aparição do componente sexual, pelo apoio" (Laplanche, 2008d, p. 44; tradução nossa). O masoquismo pode ser considerado o momento de nascimento da sexualidade humana, o estabelecimento de um circuito pulsional no próprio sujeito de tal forma a fazer circular a sexualidade do outro em si mesmo de forma controlada. Ali onde a sexualidade do outro compareceu como penetrante há, pela via do masoquismo, um tipo de apropriação que constitui o sujeito como penetrado. Tal apropriação não é consciente, mas resultado de um processo de tradução, de elaboração, daquilo que acontece ao sujeito, à sua revelia. Entendemos que essa tradução da passividade originária em termos de penetração/perfuração dá-se também graças aos códigos tradutivos e narrativas subjetivantes presentes na cultura que situam nossos corpos dentro do binarismo de gênero altamente articulado com corpos penetrados/penetrantes.

A tradução entre agressão e penetração já está presente no texto freudiano "Uma criança é espancada" (Freud, 1919/1980b), no qual ele analisa a fantasia inconsciente masoquista: "meu pai me espanca". Trata-se do segundo momento de uma sequência bem precisa, que se inicia assim com "meu pai espanca um irmão" (ou uma irmã), sendo o terceiro momento "espanca-se uma criança" (fantasia consciente). Laplanche (2015) desenvolve o momento primeiro, denotando-o com um valor de mensagem, pois o pai espanca o irmão ou a irmã na frente do sujeito que o/a detesta. Ocorre uma conclusão tradutiva, já apontada por Freud (1919/1980b), em que o sujeito acredita que se o pai bate, diante dele, nesse irmão que tanto detesta, é porque o pai apenas o ama. No entanto, "por que isso não funciona, por que o fracasso? Porque debaixo disso há algo que se expressa na conhecida frase: 'Quem ama demais castiga demais'. Amar é punir' (Laplanche, 2015, p. 128). Ou seja, no inconsciente do adulto, amar significa também, "para o genitor que espanca" (Laplanche, 2015, p. 128), copular (com a mãe) e sodomizar (o sujeito que assiste a cena de espancamento). Essa leitura do texto de Freud proposta por Laplanche só reforça a ideia de que a característica penetrável dos corpos é proveniente das mensagens dos adultos e não da natureza mesma dos corpos. 
André (1996) aponta para a necessidade "de desvincular a articulação feminilidade/passividade do discurso desvalorizador em que ela é habitualmente tomada" (p. 108). Então, quando aqui evocamos as relações entre masoquismo e complexo de perfuração, essa necessidade não diminui. O autor também reconhece que no texto "Uma criança é espancada" (Freud, 1919/1980b) é crucial no debate sobre a feminilidade e o masoquismo. Ele chama atenção para o conteúdo dessa fantasia em ser espancado que fica entre, por um lado, o desejo de ser amordaçado, e por outro, o desejo de ser rebaixado (o coitus a tergo). Esse último Freud (1919/1980b) relaciona-o à analidade e acontece paralelamente às outras fantasias como o de ser castrado, de parir um filho do pai, dentre outras. Lembremos que os argumentos de Freud (1919/1980b) se baseiam em seis pacientes, dentre os quais quatro são mulheres. Encontramos nesse texto freudiano a hipótese de que feminino é igual a ser castrado. Então, “ser castrado' não inaugura simplesmente a série de conteúdos latentes, mas fornece sua decodificação" (André, 1996, p. 110). Essa decodificação é atribuída à teoria sexual infantil que explica a diferença entre os sexos. Em outros termos, são traduções facilitadas pela cultura.

É importante dizer que o fracasso da tradução ocorre na parte mais sexual da mensagem, aquela que faz a equivalência entre "me espanca" e "me ama". Em termos metapsicológicos, é esse tipo de tradução que produz a clivagem entre um pré-consciente e um inconsciente (o que foi recalcado da mensagem, não traduzido), permanecendo no primeiro uma cicatriz relacionada ao fracasso dessa tradução. Cabe destacarmos que o caráter da mensagem comprometida com o sexual do adulto aparece de forma brutal para o eu. Então, é razoável pensarmos que os casos extremos de medo terrificante da perfuração (Bonaparte, 1936/1952b) remetem à possibilidade "de que uma mensagem seja radicalmente intraduzível. [...] O intraduzível que nos deixa estupefatos, a perturbação pelo horror" (Laplanche, 2015, p. 129).

Acreditamos que o medo da penetração, no movimento do recalcamento secundário, constitui-se nas primeiras traduções das primeiras agressões dolorosas causadas pelo adulto na situação antropológica fundamental. $\mathrm{E}$, sentida como um estranho interno, enigma intrometido em nós pela intervenção sedutora do adulto. Bonaparte (1936/1952b) aponta que o complexo de perfuração constitui-se pelo perigo permanente de sucumbir à efração, mas nossa pesquisa possibilita-nos crer que o medo é o de sucumbir ao ataque pulsional (interno), inoculado pela sexualidade inconsciente do adulto. 
Precisamos ter claro que "a sexualidade não aparece como pulsão isolada e discernível" (Laplanche , 2008b, p. 42; tradução nossa), mas é pela teoria do apoio que a função vital distancia-se de seu objeto natural e daí se perde e aparece no campo da sexualidade, do pulsional. Com isso, tiramos o véu da ideologia metabiológica do complexo de perfuração, compreendendo-o no campo da sedução generalizada, em que "o primado do outro e seu enigma não terminam necessariamente quando desaparece a relação concreta adultocriança" (Laplanche, 1999b, p. 5; tradução nossa). O sexual que continua em nós, nos ataca e nos faz fracassar na tradução, uma tradução que fracassa (parcialmente) diante do ataque interno. Em certo sentido, o medo da penetração é uma resposta ao ataque da fantasia interna, que podemos considerar uma espécie de inimiga do eu. Por conseguinte, o medo da perfuração remete também à situação de desejo de ser dilacerado, rasgado, arrombado, como assinalamos acima.

Enfim, em termos de sexualidade orificial, podemos afiançar que em cada orifício corporal, inclusive os poros da pele (Anzieu, 1968), "a relação autoconsevadora está infestada, invadida e logo completamente duplicada pelas significações sexuais" (Laplanche, 1999b, p. 133; tradução nossa). Em outras palavras, como consequência, o medo da perfuração é efeito da sedução generalizada.

\section{Conclusão}

Nosso percurso permitiu revelar que os orifícios como boca, ânus, uretra, vagina são como zonas de intercâmbio, zonas "de circulação, igualmente zonas de cuidados, isto é, os cuidados particulares e especiais" (Laplanche, 1970/1985, p. 31). Desse modo, os orifícios focalizam as fantasias parentais, sobretudo fantasias de perfuração do outro, e, paradoxalmente, também nos inocula pelo desejo de perfuração. Serão os orifícios "os pontos pelos quais se introduz na criança este corpo estranho interno que é propriamente, a excitação sexual" (p. 31). É nesse introduzir originário que localizamos a mudança no vetor de explicação do medo paralisante presente no complexo de perfuração. No pensamento bonaparteano, tal medo vem da reação celular, já a nossa concepção localiza esse medo na situação originária.

É no enigma, como centro da vida psíquica, que encontramos a origem das motivações e dos medos mais fundamentais da vida humana. Essa intromissão violenta do sexual pelo outro é traduzido pelo medo irracional da perfuração. Deste modo, reexaminamos o complexo de perfuração como 


\section{HISTÓRIA DA PSICANÁLISE}

um medo que reabre a situação de passividade originária frente ao outro. $\mathrm{O}$ medo da perfuração constitui para o eu uma tradução defensiva contra a estrangeiridade (do sexual) da mensagem endereçada pelo outro.

As situações originárias de sedução podem ser compostas de elementos de instabilidade, de agressão e de desligamento incluídos na mensagem do outro (Laplanche, 1999b). Assim, a verdade do medo da penetração vem do outro, e não da célula. Por fim, terminamos este trabalho com a sensação de que a obra bonaparteana esboça muitas possibilidades profícuas de estudos e pesquisas atuais em psicanálise, nossos esforços foram no sentido de fazer trabalhar a ideia original da autora, a partir de outros pressupostos teóricos. $\mathrm{O}$ alargamento explicativo do complexo de perfuração a partir da teoria da sedução generalizada possibilitou a mudança do vetor, da célula ao outro.

Concluímos que estudar o que Bonaparte (1936/1952b) chama de "complexo de perfuração" a partir da perspectiva laplancheana, isto é, histórico-libidinal e não biológica, abre caminho para repensar fenômenos importantes na clínica, em especial aqueles ligados à problemática da penetração não apenas no campo da sexualidade genital, mas em outros aspectos da vida psíquica.

\section{Referências}

Abraham, F. Z. (1931). Genitalumwandlung an zwei männlichen Transvestiten. Sexualwiss, 18, 223-226.

Amouroux, R. (2012). Marie Bonaparte: entre biologie et freudisme. Rennes, França: Presses Universitaires de Rennes.

André, J. (1996). As origens femininas da sexualidade. (Vera Ribeiro, trad.). Rio de Janeiro, RJ: Jorge Zahar.

Anzieu, D. (1968). De la mythologie particulière à chaque type de masochisme. Bulletin de l'Association Psychanalytique de France, 4, 84-91.

Anzieu, D. (1974). Le moi-peau. Nouvelle Revue de Psychanalyse, 9, 195-208.

Bonaparte, M. (1951). Des instincts de mort. In Introduction a la théorie des instincts ( pp. 65-85). Paris. França: PUF.

Bonaparte, M. (1952a). Passivité, masochisme et féminité. In Psychanalyse et Biologie (pp. 26-33). Paris, França: PUF. (Trabalho original publicado em 1935).

Bonaparte, M. (1952b). Vues paléobiologiques et biopsychiques. In Psychanalyse et Biologie (pp. 34-41). Paris, França: PUF. (Trabalho original publicado em 1936). 
Bonaparte, M. (1952c). De l'angoisse devant la sexualité. In Psychanalyse et Biologie (pp. 20-25). Paris, França: PUF. (Trabalho original publicado em 1948).

Bonaparte, M. (1952d). Psyché dans la nature ou des limites de la psychogenése. In Psychanalyse et Biologie. Paris, França: PUF. (Trabalho original publicado em 1950).

Bonaparte, M. (1952e). Notes sur la découverte analytique d'une scène primitive. In Psychanalyse et Biologie (pp. 146-152). Paris, França: PUF. (Trabalho original publicado em 1945).

Bonaparte, M. (1967). Sexualité de la femme. 10/18. Paris: PUF. (Trabalho original publicado em 1949).

Bonaparte, M. (1973). Some biopsychical aspects of sado-masochism. In H. M. Ruitenbeek (Ed.), The first freudians (pp.164-193). New York, NY: Jason Aronson. (Trabalho original publicado em 1945).

Cardoso, M. R. (2017). Repensando o trauma e o intraduzível com Jean Laplanche. In P. de C. Ribeiro (Org.), Por que Laplanche? (pp. 82-104). São Paulo, SP: Zagodoni.

Freud, S. (1974a). Leonardo da Vinci e uma lembrança da sua infância. In Edição Standard Brasileira das Obras Psicológicas Completas de Sigmund Freud. (J. Salomão, trad., vol. 11, pp. 69-141). Rio de Janeiro, RJ: Imago. (Trabalho original publicado em 1910).

Freud, S. (1974b). Sobre as teorias sexuais infantis. In Edição Standard Brasileira das Obras Psicológicas Completas de Sigmund Freud. (J. Salomão, trad., vol. 9, pp. 213-232). Rio de Janeiro, RJ: Imago. (Trabalho original publicado em 1908).

Freud, S. (1974c). O esclarecimento sexual das crianças. In Edição Standard Brasileira das Obras Psicológicas Completas de Sigmund Freud. (J. Salomão, trad., vol. 9, pp. 137-147). Rio de Janeiro, RJ: Imago. (Trabalho original publicado em 1907).

Freud, S. (1974d). Três ensaios sobre a teoria da sexualidade. In Edição Standard Brasileira das Obras Psicológicas Completas de Sigmund Freud (J. Salomão, trad., vol. 7, pp. 129-238). Rio de Janeiro, RJ: Imago. (Trabalho original publicado em 1905).

Freud, S. (1976). Sexualidade feminina. In Edição Standard Brasileira das Obras Psicológicas Completas de Sigmund Freud. (J. Salomão, trad., vol. 21, pp. 259-282). Rio de Janeiro, RJ: Imago. (Trabalho original publicado em 1933[1932]).

Freud, S. (1980a). O problema econômico do masoquismo. In Edição Standard Brasileira das Obras Psicológicas Completas de Sigmund Freud. (J. Salomão, trad., vol. 19, pp. 199-216). Rio de Janeiro, RJ: Imago. (Trabalho original publicado em 1924).

Freud, S. (1980b). Uma criança é espancada. Uma contribuição ao estudo da origem das perversões sexuais. In Edição Standard Brasileira das Obras Psicológicas Completas de Sigmund Freud. (J. Salomão, trad., vol. 17, pp. 223-253). Rio de Janeiro, RJ: Imago. (Trabalho original publicado em 1919). 


\section{HISTÓRIA DA PSICANÁLISE}

Freud, S. (1980c). O tabu da virgindade: contribuições à psicologia do amor III. In Edição Standard Brasileira das Obras Psicológicas Completas de Sigmund Freud. (J. Salomão, trad., vol. 11, pp. 179-192). Rio de Janeiro, RJ: Imago. (Trabalho original publicado em 1918[1917]).

Freud, S. (1980d). O inconsciente. In Edição Standard Brasileira das Obras Psicológicas Completas de Sigmund Freud. (J. Salomão, trad., vol. 14, pp. 191-239). Rio de Janeiro, RJ: Imago. (Trabalho original publicado em 1915).

Freud, S. (1996a). Inibições, sintomas e ansiedade. In Edição Standard Brasileira das Obras Psicológicas Completas de Sigmund Freud. (J. Salomão, trad., vol. 19, pp. 107-200). Rio de Janeiro, RJ: Imago. (Trabalho original publicado em $1926[1925])$.

Freud, S. (1996b). Algumas consequências psíquicas da distinção anatômica entre os sexo. In Edição Standard Brasileira das Obras Psicológicas Completas de Sigmund Freud. (J. Salomão, trad., vol. 19, pp. 303-320). Rio de Janeiro, RJ: Imago. (Trabalho original publicado em 1924).

Freud, S. (1996c). A dissolução do complexo de Édipo. In Edição Standard Brasileira das Obras Psicológicas Completas de Sigmund Freud. (J. Salomão, trad., vol. 19, pp. 217-228). Rio de Janeiro, RJ: Imago. (Trabalho original publicado em 1924).

Freud, S. (1996d). A organização genital infantil: uma interpretação na teoria da sexualidade. In Edição Standard Brasileira das Obras Psicológicas Completas de Sigmund Freud. (J. Salomão, trad., vol. 19, pp. 179-188). Rio de Janeiro, RJ: Imago. (Trabalho original publicado em 1923).

Lanouzière, J. (1991). Marie Bonaparte. In Histoire secrète de la séduction sous le règne de Freud. (pp. 123-153). Paris, França: PUF.

Laplanche, J. (1985). Vida e morte em psicanálise. (C. P. B. Mourão e C. F. Santiago, trads.). Porto Alegre, RS: Artes Médicas. (Trabalho original publicado em 1970).

Laplanche, J. (1988). Problemáticas II: castração, simbolizações. (Álvaro Cabral, Trad.). São Paulo, SP: Martins Fontes. (Trabalho original publicado em 1980).

Laplanche, J. (1992). Novos fundamentos para a psicanálise. (C. Berliner e E. Brandão, trads.). São Paulo, SP: Martins Fontes.

Laplanche, J. (1999a). La sexualité humaine, biologisme et biologie. Le plessisRobinson, Institut Synthélabo.

Laplanche, J. (1999b). Séduction, persécution, révélation. In Entre séduction et inspiration: l'homme (pp. 7-56). Paris, França: Quadrige/PUF.

Laplanche, J. (2006). Problématiques VII: Le fourvoiement biologisant de la sexualité chez Freud, suivi de Biologisme et biologie. Paris, França: PUF.

Laplanche, J. (2008a). Implantation, intromission. In La révolution copernicienne inachevée (Travaux 1967-1992) (pp. 355-358). Paris, França: PUF. 
Laplanche, J. (2008b). La position originaire du masochisme dans le champ de la pulsion sexuelle. In La révolution copernicienne inachevée (Travaux 1967-1992). (pp. 37-58). Paris, França: PUF.

Laplanche, J. (2008c). Masochisme et théorie de la séduction généralisée. In La révolution copernicienne inachevée (Travaux 1967-1992) (pp. 439-456). Paris, França: PUF.

Laplanche, J. (2008d). Ponctuation: La pulsion et son objet-source: son destin dans le transfert. In La révolution copernicienne inachevée. (Travaux 1967-1992) (pp. 227-242). Paris, França: Quadrige/PUF.

Laplanche, J. (2015). Sexual: a sexualidade ampliada no sentido freudiano (20002006). (V. Dresch e M. Marques, trads.). Porto Alegre, RS: Dublinense.

Le Bon, G. (1875). Physiologie de la génération de l'homme et des principaux êtres vivants. Paris, França: Alfred Duquesne Éditeur.

Le Bon, G. (1911). Les opinions et les croyances. Paris, França: Flammarion.

Lebovici, S. (1983). À propos de l'oeuvre scientifique de Marie Bonaparte. Revue Française de Psychanalyse, 47(4), 1081-1093. Recuperado de: <https://gallica. bnf.fr/accueil/fr/content/accueil-fr?mode=desktop $>$.

Marañón, G. (1931). L'évolution de la sexualité et les états intersexuels. Paris, França: Gallimard.

Ribeiro, P. de C. (2016). O sexual, o fálico e o orificial a partir da teoria da sedução generalizada. Percurso, 56/57, 105-112.

Ribeiro, P. de C. (2017). Gênero, sexo e enigma no sexual de Jean Laplanche. In P. de C. Ribeiro (Org.), Por que Laplanche? (pp. 105-124). São Paulo, SP: Zagodoni.

Ribeiro, S. D., \& Belo, F. R. R. (2017). Os 201 clitóris de Marie Bonaparte. Reverso, 74(39), 61-67.

Silva, M. K. (2012). A feminilidade originária nas psicoses. Dissertação de Mestrado, Faculdade de Filosofia e Ciências Humanas, Universidade Federal de Minas Gerais, Belo Horizonte.

Tarelho, L. C. (2016). A tópica da clivagem e o supereu. Percurso, 56/57, 133-142.

Tarelho, L. C. (2017). O descentramento do ser humano e o realismo do inconsciente na teoria laplancheana. In P. de C. Ribeiro (Org.), Por que Laplanche? (pp. 15-49). São Paulo, SP: Zagodoni. 


\section{HISTÓRIA DA PSICANÁLISE}

\section{Resumos}

(Piercing complex: an interpretation based on the theory of generalized seduction)

We approach the piercing complex based on the theory of generalized seduction, with a focus on the so-called "orificial sexuality" and on parental fantasies, especially the piercing of the orifices, which eventually inoculate the fear of perforation in the child. We believe that the fear of piercing refers to the reality of the message (coming from the adult) and urges the child to translate the internal foreign body that is actually introduced into it, namely sexual stimulation. It is in this original penetration (of the message of the other) that we locate the change in the vector of explanation of the paralyzing fear found in the piercing complex, which according to Bonapartean thinking stems from a protocellular reaction.

Key words: Message, piercing, seduction, translation

(Complexe de perforation: une interprétation de la théorie de la séduction généralisée)

Nous abordons le complexe de la perforation à travers la théorie de la séduction généralisée en focalisant notre intérêt sur la sexualité dite orificielle et les fantasmes parentaux, en particulier les effractions des orifices, qui finissent par inoculer la peur de la perforation à l'enfant. Nous soutenons que la peur de la perforation fait référence à la réalité du message (émanant de l'adulte) et incite l'enfant à traduire le corps étranger interne qui est proprement intromis en elle, à savoir l'excitation sexuelle. Et c'est dans cette pénétration originale (du message de l'autre) que nous localisons un changement du vecteur d'explication de la peur paralysante présente dans le complexe de perforation qui, selon la pensée bonapartéenne, provient de la réaction protocellulaire.

Mots clés: Message, perforation, séduction, traduction

(Complejo de perforación: una interpretación a partir de la teoría de la seducción generalizada)

Abordamos el complejo de perforación a través de la teoría de la seducción generalizada, enfocándonos en la llamada sexualidad de los orificios y en las fantasías parentales, sobre todo en la de el allanamiento de los orificios, que acaban inoculando en el niño el miedo de la perforación. Consideramos que el temor de la perforación remite a la realidad del mensaje (venida del adulto) e incita al niño a traducir el cuerpo extraño interno, que es propiamente entrometido en él, a saber, la excitación del sexual. Y es en dicha penetración originaria (del mensaje del otro) donde encontramos el cambio en el vector de explicación del miedo paralizante presente en el complejo de perforación, que en el pensamiento bonaparteano sale de la reacción de una protocélula.

Palabras clave: Mensaje, perforación, seducción, traducción 
(Perforationskomplex: Eine Interpretation anhand der allgemeinen Verführungstheorie)

Dieser Artikel analysiert den Perforationskomplexes anhand der allgemeinen Verführungstheorie. Dabei werden die auf die Körperöffnungen bezogene Sexualität und die Urfantasien behandelt, vor allem in Hinsicht auf dem Bohren von Öffnungen, was dazu führt, dass das Kind die Perforationsangst verinnerlicht. Es wird angenommen, dass die Perforationsangst ein Verweis ist auf die Realität der Botschaft (vom Erwachsenen), was das Kind dazu antreibt, den internalisierten Fremdkörper, der in ihm eingeführt wird, zu übersetzen, und zwar als Erregung des Sexuellen. In diesem ursprünglichen Eindringen (der Botschaft des Anderen) finden wir die Änderung des Erklärungsmuster der im Perforationskomplex bestehenden lähmenden Angst, welche gemäß der Theorie von Marie Bonaparte von einer protoplasmatischen Reaktion hervorgerufen wird.

Schlüsselwörter: Botschaft, Perforation, Verführung, Übersetzung

Citação/Citation: Ribeiro, S. D., \& Belo, F. R. R. (2019, setembro). Complexo de perfuração: uma interpretação a partir da teoria da sedução generalizada. Revista Latinoamericana de Psicopatologia Fundamental, 22(3), 584-605. htttp://dx.doi.org/10.1590/ 1415-4714.2019v22n3p584.10

Editora/Editor: Profa. Dra. Ana Maria Rudge

Submetido/Submitted: 10.1.2019 / 1.10.2019 Versão Revisada/Revised Date: 4.3.2019 / 3.4.2019

Aceito/Accepted: 5.5.2019 / 5.5.2019 


\section{HISTÓRIA DA PSICANÁLISE}

Copyright: (C) 2009 Associação Universitária de Pesquisa em Psicopatologia Fundamental/ University Association for Research in Fundamental Psychopathology. Este é um artigo de livre acesso, que permite uso irrestrito, distribuição e reprodução em qualquer meio, desde que o autor e a fonte sejam citados / This is an open-access article, which permits unrestricted use, distribution, and reproduction in any medium, provided the original authors and sources are credited.

Financiamento/Funding: Este trabalho teve apoio da Coordenação de Aperfeiçoamento de Pessoal de Nível Superior (Capes) (Brasília, DF, Br) / This work was supported by the Coordenação de Aperfeiçoamento de Pessoal de Nível Superior (Capes) (Brasília, DF, Br).

Conflito de interesses/Conflict of interest: Os autores declaram que não há conflito de interesses / The authors declare that there is no conflict of interest.

\section{SARUg DAGiR Ribeiro}

Doutoramento em Psicologia na Universidade Federal de Minas Gerais - UFMG (Belo Horizonte, MG, Br); Mestre em Letras; Psicóloga clínica.

Rua 36, n. 320, bloco 2, apto.104 - Gávea 2

33200-000 Vespasiano, MG, Br

sdagir@gmail.com

https://orcid.org/0000-0001-8251-6710

\section{FÁBio Roberto Rodrigues Belo}

Doutor em Literatura Brasileira pela Universidade Federal de Minas Gerais - UFMG (Belo Horizonte, MG, Br); Mestre em Psicologia; Psicólogo e Professor Adjunto de Psicologia da Universidade Federal de Minas Gerais - UFMG (Belo Horizonte, MG, Br). Bolsista produtividade em pesquisa $\mathrm{CNPq}$ - nível 2.

Rua Germano Torres, 166/707 - Cruzeiro

30310-040 Belo Horizonte, MG, Br

fabiobelo76@gmail.com

https://orcid.org/0000-0002-5803-1745

This is an open-access article, which permits unrestricted use, distribution,

\section{(cc) BY-NC}

and reproduction in any medium for non-commercial purposes provided the original authors and sources are credited. 